\title{
FINITE ELEMENT ANALYSIS OF DISSIMILAR WELDING BETWEEN NEWLY DEVELOPED CR-FREE NICKEL BASED WELDING ELECTRODE AND STAINLESS STEEL AISI 304
}

\author{
Nataraj. J.R ${ }^{1}$, M.krishna ${ }^{2}$, G.R.Rajkumar ${ }^{2}$ \\ ${ }^{1,2,3}$ Dept. of Mechanical Engg, R.V.College of Engineering, Bangalore-59, India, nataraj_jr@yahoo.com
}

\begin{abstract}
TIG welding is a popular joining method for stainless steel (SS) which contains 16-18\% of Cr and is responsible for its corrosion resistance and good mechanical properties. The SS welding electrode is over alloyed with 18-22\% of Cr. During TIG welding, fumes containing carcinogenic hexavalent $\mathrm{Cr}^{+6}$ are generated which are mainly from the electrode rather than the base metal and this affects the health of the welder. To mitigate these problem eight versions of nickel based Cr-free electrode materials were developed. After extensive literature survey and discussions with welding expert's chemical composition of filler rod (electrode) is decided such that the weld joint should have good mechanical properties. It is well known fact that structural components in addition to structural loads also experience welding induced residual stress. Presence of residual stresses may be favorable or harmful for the structural components depending on their nature and magnitude. Hence the main focus of the study is to perform Finite Element Analysis to understand the complete nature of residual stresses and distortions in butt welded joints using the eight novel Cr-free electrodes with base plates AISI SS304 and to determining the best weldment combination. Ansys 13, a finite element (FE) based commercial software, sequentially coupled transient thermal-mechanical, three dimensional finite element models were developed and the simulation was done using elemental birth and death technique. After the FE analysis it was seen that though the variation in distortions were not considerable by virtue of restraints, the stresses in each variety of the weld showed notable variations of about 30MPabetween the best and the least preferred composition.
\end{abstract}

Keywords: FEA, Residual Stresses, Butt weld, Cr-Free Nickel Electrodes, AISI 304 Stainless Steel.

\section{INTRODUCTION}

AISI 304 stainless steel (SS) has excellent properties like high strength to weight ratio, high ductility, excellent drawing, forming and spinning properties, so it is used in applications like chemical equipment, food industries, coal hopper, power plant, marine equipments and etc. It is essentially a low carbon steel which contains $18 \%$ chromium $(\mathrm{Cr})$ by weight. It is this addition of $\mathrm{Cr}$ that gives steel its unique corrosion resistance properties. Due to these excellent mechanical properties and balanced austenitic structure SS is often used in fabrication industries. When they are fabricated into structures, SS components are often joined by welding. Though SS have excellent corrosion resistance when heated to temperatures between $450-900^{\circ} \mathrm{C}$ (typical welding temperature) $\mathrm{Cr}$ depletion occurs and is now vulnerable to corrosion. Hence most of the conventional SS electrodes are over alloyed with $\mathrm{Cr}$ to make up for this loss. The National Institute of Occupational Safety and Health (NIOSH) have noticed that, $\mathrm{Cr}^{+6}$ fumes generating in welding of SS and suspected them as carcinogens which poses serious risk to the welder's health [1]. Conventional SS filler material contributes in a predominant way in generating $\mathrm{Cr}^{+6}$ fume than the base metal, although base metal diluted into the weld can also end up in the fume but not more than that of filler material. Many proposed solutions like exhaust systems, masks etc. are expensive and not very practical. Occupational Safety and Health Administration (OSHA) in United States recommend $\mathrm{Cr}$ Free welding of SS. Therefore $\mathrm{Cr}$-free nickel electrodes have the potential to offer a permanent solution to the problem. However during welding a very complex thermal cycle is applied to the weldment which in turn causes irreversible elastic- plastic deformation and consequently gives rise to the residual stresses and distortions in and around fusion zone and heat affected zone (HAZ). Presence of residual stresses may be beneficial or harmful for the structural component depending on the nature and magnitude. The residual stresses also affect the creep and fatigue life and may lead to stress corrosion cracking. Further the use of a dissimilar joint may lead to metallurgical and diffusion effects complicating the problem. Therefore the analysis of the weldments for residual stresses and distortions is the required. Many expensive techniques like measuring residual stresses in metals including stress relaxation techniques, diffraction techniques, cracking techniques and techniques by use of stress sensitive properties are extensively used. However, these techniques cannot obtain complete stress distribution and most of them are costly and time consuming and some of the 
tests are destructive. However FEM being one of the conventional methods that can be applied to determine residual stresses and distortion for the most complex and real time applications in a cost effective way.

The prediction of weld residual stress has been the subject of many investigators. Finite element analysis (FEA) has been used by many researchers to perform welding simulations and to predict weld residual stresses in different types of joints and materials. This prediction is very difficult due to the complex variations of temperature as a consequence of heat input with respect to time (transient analysis), variation of stresses state arising which is a function of temperature, thermal contraction and expansion, and variation of material properties with time and space. Gurinder Singh Brar [2] performed finite Element Simulation of Residual Stresses in Butt Welding of Two AISI 304 Stainless Steel Plates. MatoPerić et al [3] made a Comparison of Residual Stresses in Butt-Welded Plates Using Software Packages Abaqus and Ansys. M Jeyakumar et al [4] closely examined the differences between a 2D plane stress and a $3 \mathrm{D}$ analysis. All the models discussed above simple hypothesis was assumed, however it was stated that 2D modeling was unable to capture the nuances of 3D modeling, for instance variation of stress along thickness, electrode movement etc. In a work by LI YAJIANG et al [5], who investigated the distribution of the residual stress in the gas shielded arc weld joint of HQ130 grade high strength steel using ANSYS software and in the study carried out by Andrea Capriccioli and Paolo Frosi[6] related to a large sensitivity analysis the importance of dynamic mesh were explained. Further in most of the models sequentially coupled analysis was implemented. Deng et al [7] compared two steels with $0.15 \% \mathrm{C}$ and $0.44 \% \mathrm{C}$ with martensite start and end temperatures of $476 \mathrm{oC}$ and $328 \mathrm{oC}$ respectively and found that there was virtually no difference in the longitudinal residual stress distribution whether or not phase transformation was considered in low carbon steel. Also Cheng [8] studied the butt weld with and without restraint for heat treatable aluminum alloys. It was shown that the models with restraint showed a higher value of stress and lesser distortion whereas models without restraints in which only the rigid body motion was constrained showed lesser stress and higher distortion. In all the above mentioned works, the birth and death technique was extensively used.

\section{SIMULATION OF WELDING PROCESS}

In the present study, the butt-weld joint of two AISI 304 stainless steel plates with $\mathrm{Ni}$ weld bead ( electrode compositions is shown in table 3 ) is modeled using a commercially available finite element software. Joint made by two plates of $6 \mathrm{~mm}$ thick and $120 \mathrm{~mm}$ wide (along the welding direction) was considered. The weld-groove angle is $80^{\circ}$. Various dimensions of the butt welded joint are shown in Fig. 1(a). Mesh consists of solid hexahedron 8-node element which is solid 278 for thermal analysis and solid 185 for structural analysis. The contact elements used was contac173 and target element used was targe170. Mesh control is applied to the weldment area. Heat convection was allowed at all the surfaces. Structural boundary conditions with the meshed isometric view of the two butt welded plates is shown in figure 1(b).

a

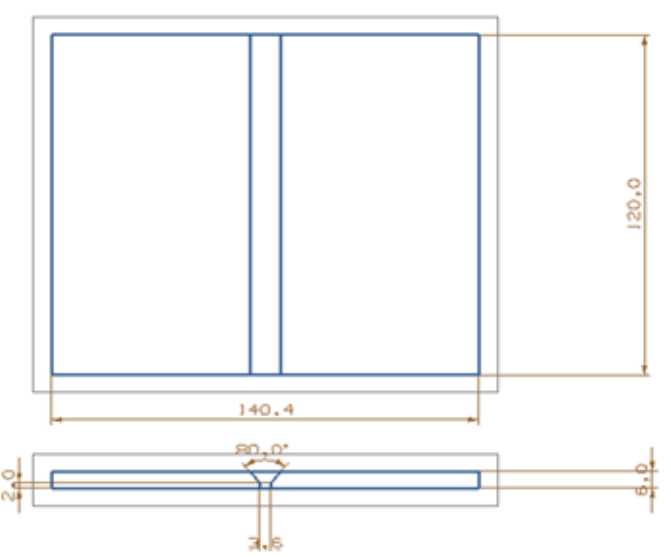

Fig 1(a) Shows the dimensions of the butt welded joint

\subsection{ASSUMPTIONS AND BOUNDARY CONDITIONS IN THE THERMO-MECHANICAL}

\section{ANALYSIS}

1. Material is isotropic and is at initial room temperature of $30^{\circ} \mathrm{C}$.

b.

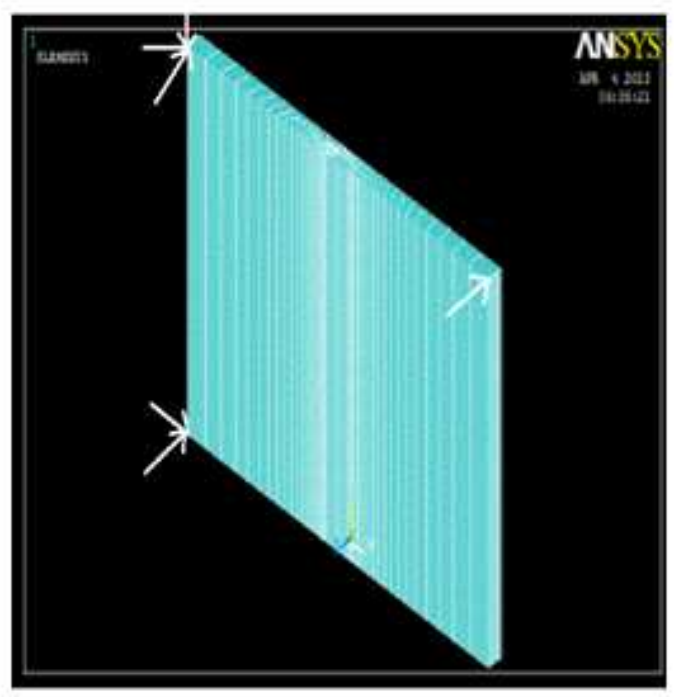

Fig 1(b) Shows Structural boundary conditions 
2. The materials properties of filler alloys are temperature dependent and generated using JMAT PRO materials simulation software.

3. The displacements of the parts, during the welding, do not affect the thermal distribution of the parts themselves.

4. All the material properties are described upto the liquid phase of metal.

5. Effects of phase change and diffusion are ignored

6. Convection effects are considered $\left(20 \mathrm{~W} / \mathrm{m}^{2} \mathrm{~K}\right)$ and radiation effects are neglected owing to the high nonlinearities and radiation heat transfer has little or no effect on the thermal cycle.

7. Creep deformation is regarded as negligible.

8. The analysis is considered elastic. Hence the local deformations are a sum of elastic and thermal

9. The effect of kinematic hardening or isotropic strain hardening is neglected and Bauschinger's effect deformations are not considered.

To simplify the welding simulation, it is computationally efficient to perform thermal and mechanical analyses separately. First the computation of the temperature history during welding and subsequent cooling is completed and this temperature field is applied to the mechanical model as a body force to perform the residual stress analysis. The heat input during welding is modeled in commercially available software by the equivalent heat input which includes body heat flux.

Table 1: Compositions of Eight Chromium Free Electrodes

\begin{tabular}{|c|c|c|c|c|c|c|c|c|c|}
\hline \multirow{2}{*}{$\begin{array}{c}\text { Alloy } \\
\text { Type }\end{array}$} & \multicolumn{8}{|c|}{ Composition of the Weld Electrodes in \% wt } \\
\cline { 2 - 11 } & Ni & Al & Co & Mo & Cu & Fe & Mn & Ti & C \\
\hline $1 \mathrm{~S}$ & 39.999 & 0.5 & 0 & 20 & 10 & 22 & 6.5 & 1 & 0.001 \\
\hline $2 \mathrm{H}$ & 43.499 & 0.5 & 0 & 20 & 10 & 25 & 0 & 1 & 0.001 \\
\hline $3 \mathrm{~N}$ & 33.499 & 0.5 & 10 & 10 & 10 & 25 & 0 & 1 & 0.001 \\
\hline $4 \mathrm{~S}$ & 43.499 & 0.5 & 10 & 10 & 10 & 23 & 2 & 1 & 0.001 \\
\hline $5 \mathrm{~N}$ & 43.499 & 0.5 & 14 & 6 & 10 & 23 & 2 & 1 & 0.001 \\
\hline $6 \mathrm{~N}$ & 43.499 & 0.5 & 12 & 8 & 10 & 23 & 2 & 1 & 0.001 \\
\hline $7 \mathrm{~N}$ & 43.499 & 0.5 & 8 & 12 & 10 & 23 & 2 & 1 & 0.001 \\
\hline $8 \mathrm{~N}$ & 43.499 & 0.5 & 6 & 14 & 10 & 23 & 2 & 1 & 0.001 \\
\hline $9 \mathrm{~N}$ & 43.499 & 0.5 & 16 & 4 & 10 & 23 & 2 & 1 & 0.001 \\
\hline
\end{tabular}

The amount of heat input, Q has been calculated by using empirical relation shown in Equ. 1.

$$
\mathrm{Q}=\eta \mathrm{VI}
$$

Where $\mathrm{Q}$ is heat flux applied $\left(\mathrm{W} / \mathrm{m}^{2}\right), \eta$ is efficiency $(70 \%), \mathrm{V}$ is voltage (20 volts) and $\mathrm{I}$ is current (115amps). To simulate the moving heat source, model of the heat source was done for every time steps. In the present work moving heat source was simplified by making the weld arc stay at every element and induces constant heat flux. After the allotted time interval the heat source was moved to the next element and made to induce the heat. Similar movement of the heat source till the end of the base plate resembles the welding simulation.

\section{RESULTS AND DISCUSSIONS}

\subsection{Temperature Distribution and Distortion}

The figure 2(a) and 2(b) shows the temperature distribution and distortion for a typical 3S/SS304 weld joint for 23.2 seconds which is followed by a number of steps simulating the cooling stage which will last up to 1800 s. A maximum temperature of $1412.20 \mathrm{C}$ is seen at the end of the weld. It also shows the molten pool shape around the high-energy heat source in the form of ellipse on the surface of the weld plate. The first stage is a transient thermal field attained often called the initiation or starting stage followed by a quasi-stationary stage at which the temperature distribution is stationary in which the co-ordinate system moving with the heat source. That is the volume of the weld pool expands until a quasisteady state is reached. A second transient stage occurs during which the temperature profile decreases after the heat source is extinguished, this stage is also called as ending stage.

a.

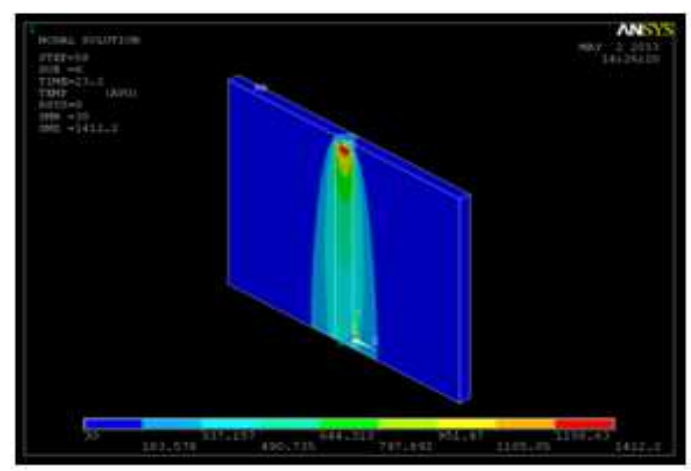

Fig 2(a) Shows temperature contours at the end of 23.2 seconds for $3 \mathrm{~N} / \mathrm{SS} 304$

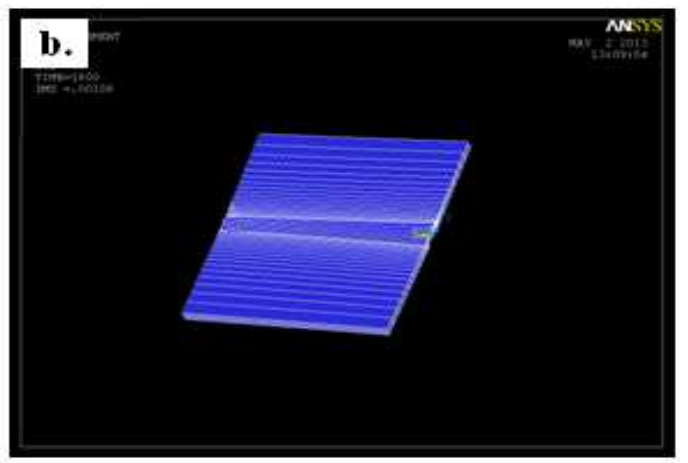

Fig 2(b) shows distortion in the weld joint for $3 \mathrm{~N} / \mathrm{SS} 304$ 


\subsection{Distortions in the Weld}

Since the plates are not allowed to move freely in the $\mathrm{Z}$ direction the distortion is seen in the plane of the plate. The hot area tries to expand more or less evenly in all directions. The metal behind the heat source is already solidified and cooled down to the temperatures where it is able to withstand loads. The gap closes because the hot part situated near the arc is expanding, but the cold part of the plate is struggling against it. The plate edges behind the source do not have a chance to expand freely in all directions. The only way for metal to move is to travel forward, closing the gap ahead of the source leading to rotational distortion as seen in figure 2(b). Table 2 compares the distortion of various joints. As seen from the table 2, joint 2H/SS304 exhibits least distortion.

\subsection{Residual Stresses}

\subsubsection{Longitudinal Residual Stress}

Stress acting parallel to the direction of the weld bead is termed as longitudinal residual stress, as denoted by the letter $\sigma y$. Longitudinal stress distribution along in the joint for the weld joint 3N/SS304 is shown in the figure 3(a) and plot of longitudinal stress for various joints from the weld line.

\begin{tabular}{|l|l|l|}
\hline \multicolumn{3}{|c|}{ Table 2. Values of distortion (vector sum)for various } \\
joints
\end{tabular}

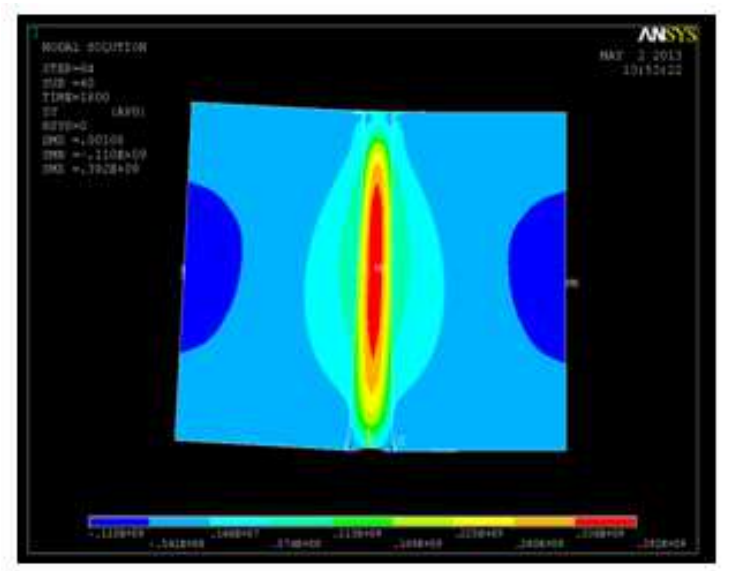

Fig 3 (a) longitudinal residual Stress contours for the joint $3 \mathrm{~N} / \mathrm{SS} 304$

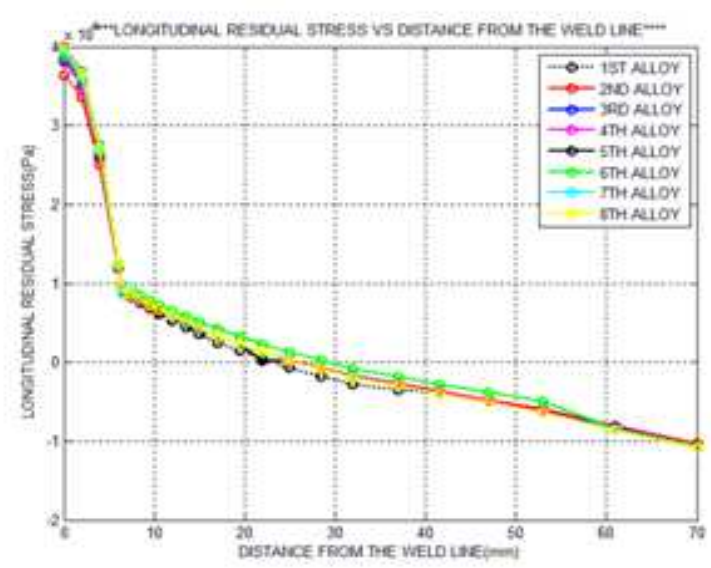

Fig 3 (b) Plot of longitudinal stresses stress values for various joints.

Due to cooling, the areas close to the weld contract and cause tensile stresses, that is as the weld pool contracts during cooling, the material adjacent offers resistance there by creating tensile stress in the middle region. After a certain time, the temperature change due to welding diminishes. High tensile longitudinal stresses (usually up to the yielding stress) are produced near the weld. In the regions further away from the weld, compressive stresses do exist as shown in the figure 3(a). Plot of longitudinal stresses for all eight joints types are shown in figure 3 (b) and magnitude of longitudinal stresses at the weld center is shown in Table 3 . The alloy $2 \mathrm{H}$ shows least stress while $8 \mathrm{~S}$ shows highest stress.

\begin{tabular}{|l|l|l|}
\hline \multicolumn{2}{|l|}{ Table 3. Longitudinal Residual Stresses at the Weld Center } \\
\hline Slno & Joint Type & $\begin{array}{c}\boldsymbol{\sigma}_{\mathbf{y}} \text { in } \\
\text { (iPa) }\end{array}$ \\
\hline 1 & $1 \mathrm{~S} / \mathrm{SS} 304$ & 380.9 \\
\hline 2 & $2 \mathrm{H} / \mathrm{SS} 304$ & 363.6 \\
\hline 3 & $3 \mathrm{~S} / \mathrm{SS} 304$ & 385.27 \\
\hline 4 & $4 \mathrm{~N} / \mathrm{SS} 304$ & 383.5 \\
\hline 5 & $5 \mathrm{~N} / \mathrm{SS} 304$ & 399.94 \\
\hline 6 & $6 \mathrm{~N} / \mathrm{SS} 304$ & 389.68 \\
\hline 7 & $7 \mathrm{~N} / \mathrm{SS} 304$ & 394.02 \\
\hline 8 & $8 \mathrm{~N} / \mathrm{SS} 304$ & 394.22 \\
\hline
\end{tabular}

\subsubsection{Transverse Residual Stresses}

A stress acting perpendicular to the direction of the weld bead is known as transverse residual stress, denoted by the letter $\sigma \mathrm{x}$. Transverse stress distribution along in the alloy $3 \mathrm{~N}$ welded with SS304 is shown in the figure 4 (a). As seen from the contour plot of transverse residual stress the maximum tensile stresses occur in the middle region where as maximum compressive stresses occur at the ends. During welding of 
short and narrow plates with a high welding speed, the plate edges move towards each other during cooling.

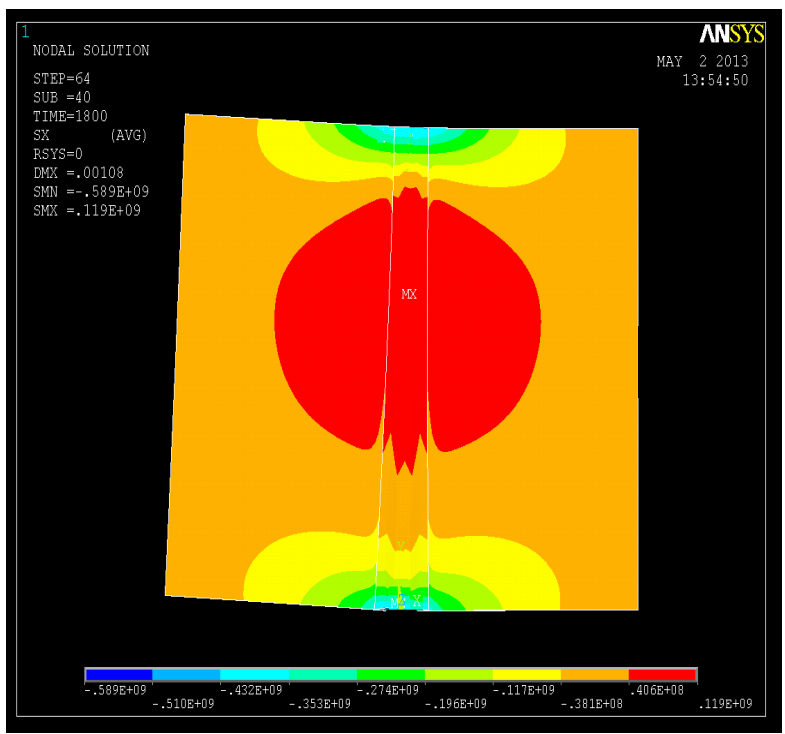

Fig 4(a).Transverse Residual Stress Contours for joint $3 \mathrm{~N} / \mathrm{SS} 304$

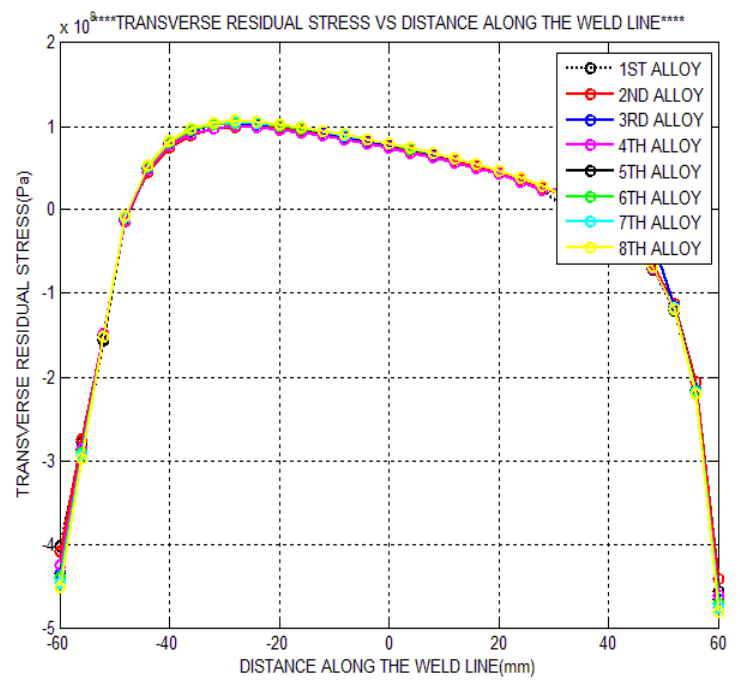

Fig 4(b) Plot of Transverse Stress for all eight type of Joints

The longitudinal shortening tries to bend plates in the plane. As a result, the residual stresses illustrated in figure 4 (a) are formed along the weld centerline. Figure 4 (b) shows the transverse residual stress distribution along the weld line for all eight joints welded to SS304. Also, the plot of transverse stresses doesn't show a uniform variation with respect to any filler metal type. That is each alloy may prove to be better at certain places along the weld joint.

\section{CONCLUSIONS}

From the FEA analysis of the eight joints welded with new chromium free fillers with SS304base plates, the following conclusions are drawn,

1. In case of temperature distribution the second alloy recorded the highest possible temperature which was around $1573.81^{\circ} \mathrm{C}$.

2. The value of tensile longitudinal stresses is twice that of maximum transverse stresses. Hence it could be concluded that longitudinal stresses play a more crucial role in the case of failure of the specimen, for instance by fatigue, stress corrosion cracking etc.

3. In case of transverse stresses alloys $2 \mathrm{H}, 1 \mathrm{~S}$ and $4 \mathrm{~S}$ stand out to be the three best compositions, each showing least value of tensile stress at different regions of the weld.

4. The value of tensile longitudinal residual stress is least for $2 \mathrm{~N}$. It is around $33 \mathrm{MPa}$ lower than $5 \mathrm{~N}$ in case of SS304, $5 \mathrm{~N}$ being the alloy having the greatest tensile longitudinal residual stress.

5. Distortion vector sum in the weld was observed in the plane of the weld however it was a minute value around one $\mathrm{mm}$. The least distortion was observed in case of $2 \mathrm{~N}$ and highest in case of $8 \mathrm{~N}$.

\section{REFERENCES}

[1] Criteria for a recommended standard occupational exposure to hexavalent chromium,Department of Health and human servicescenters for disease control and prevention, National Institute for occupational Safety and Health, Publication No. 2013-128, January 2013

[2] Gurinder Singh Brar, Finite element simulation of residual stresses in Butt welding of Two AISI 304 stainless steel plates, International Journal on Theoretical and Applied Research in Mechanical Engineering (IJTARME), Volume-2, Issue-1, 2013, $2319-3182$

[3] MatoPerić,

DragiStamenković, ViliMilković,Comparison of Residual Stresses in ButtWelded Plates Using Software Packages Abaqus and Ansys, Scientific Technical Review, Vol.60,No.3-4, 2010, pp.22-26

[4] M. Jeyakumar, T Christopher, R Narayanan and B NageswaraRao, Residual stress evaluation in butt welded steel plates, International journal of engineering and materials sciences, vol.18, December 2011, pp. 425- 434,

[5] Li Yajiang, Wang Juan, Chen Maoaiand ShenXiaoqin, Finite element analysis of residual stress in the welded zone of high strength steel, Bull. Mater. Sci., Vol. 27, No. 2, April 2004, pp. 127-132 
[6] Andrea Capriccioli, Paolo Frosi,Multipurpose ANSYS FE procedure for welding processes simulation,Fusion Engineering and Design 84 , Feb. $2009,546-553$

[7] Deng et al, FEM prediction of welding residual stress and distribution in $\mathrm{C}$ steel considering phase change effect,Materials design, volume 30, issue 2, Feb. 2009, pages 359-366

[8] C.M Cheng,Butt -welding residual stress of heat treatable aluminum alloys, Journal of Material Science Technology., Vol. 23, issue 2, 2007 , pp. 217-222

\section{BIOGRAPHIES}

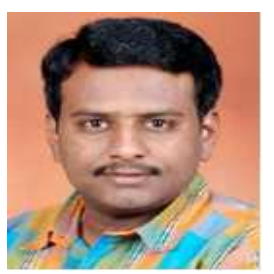

J. R. Nataraj has obtained his Bachelors in Mechanical engineering degree from Gulbarga University and M.Tech from University of Applied Sciences Wildau, Berlin, Germany. He is currently working as Asst Professor at R.V. Engineering, Bangalore. He is pursuing $\mathrm{PhD}$ under the guidance of Dr. M. Krishna. He has five international journals and eight International conference to his credit. His research interests are New Materials Development and welding.

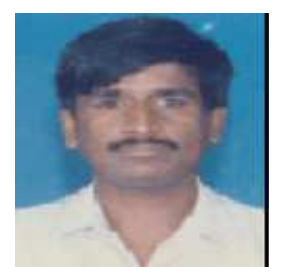

Dr M Krishna, He has acquired MS from BITS Pilani, Madhya Pradesh, India and Ph.D. in Materials Science, Mangalore University, Mangalore, India. $\mathrm{He}$ is working in the area of Composites, Alloys, Corrosion \& electroplating. He has published more than 100 research papers in international refereed journals; $\mathrm{He}$ is a recipient of ARCI Best Paper Award \& Best Presentation Award, at NSSRS-4, 2002, IIT Madras, Chennai. Best Faculty award2004 by Dept. of Mech. Engg., R V College of Engineering, Bangalore. Award of Who's Who, his name listed in Marquis Who's Who in Science and Technology, USA, 2004 and Living Science Award by International bio-graphical Centre, Cambridge, United Kingdom, 2004 for his contributions to the field of Research and Education. Presently he is the Director of CMRTU (R\&D) and Professor of Dept. of Mechanical Engg, R V College of Engg, Bangalore, India.

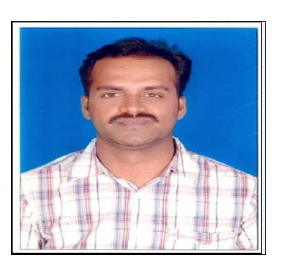

Mr. G. R. Rajkumar, has obtained BE degree from Bangalore university and M.Tech degree from Kuvempu university, presently working as Assistant Professor at R.V.College of Engineering. Bangalore. He is pursuing Ph.D at Mangalore University under the guidance of Dr. M. Krishna. He published papers in three international conference and two international journals. His area of interest involves polymer composites, fiber metal laminates and cryogenic machining. 